\title{
Hepatitis B Virus Genotypes: Do They Play a Role in the Outcome of HBV Infection?
}

See Article on Page 865

$\mathrm{H}$ epatitis B virus (HBV) has been classified into 8 genotypes $(\mathrm{A}-\mathrm{H})$ based on an intergroup divergence of $8 \%$ or more in the complete nucleotide sequence. ${ }^{1,2}$ Figure 1 illustrates the geographic distribution of HBV genotypes, but existing information is incomplete, as data in many parts of the world are not available or are based on very small numbers of patients studied. Additionally, the distribution of HBV genotypes may vary with time and with population migration, as demonstrated in a recent study in the United States. ${ }^{3}$ Furthermore, subtypes have now been identified within some genotypes.

In the 2.5 years since our last editorial, ${ }^{1}$ there has been an explosion of knowledge in the literature on the epidemiology of HBV genotypes, and their association with hepatitis $\mathrm{B}$ e antigen $(\mathrm{HBeAg})$ seroconversion, activity of liver disease, and treatment response.

\section{HBV Genotypes, HBeAg Seroconversion and Outcome of Chronic HBV Infection}

Most of the information on the clinical significance of $\mathrm{HBV}$ genotypes has been based on studies of patients with chronic HBV infection in Asia. Because of the preponderance of genotypes $\mathrm{B}$ and $\mathrm{C}$ in Asian countries, the studies are restricted to comparisons of patients with these two genotypes. Nevertheless, such comparisons provide very important information on the relation between HBV genotype $\mathrm{B}$ and $\mathrm{C}$ and the rate of progression of liver disease, since the age at the onset of infection is presumed to be the same (perinatal period) in the vast majority of patients. These studies clearly showed that compared to genotype $\mathrm{C}$, HBV genotype $\mathrm{B}$ is associated with spontaneous $\mathrm{HBeAg}$ seroconversion at a younger age, less active liver disease, and a slower rate of progression to cirrhosis. ${ }^{4-9}$ Some studies also found that genotype B patients are less likely to have hepatitis flares and more likely to remain in remission after HBeAg seroconversion. ${ }^{9}$ Most studies, in-

Abbreviations: $H B V$, hepatitis B virus; HCC, hepatocellular carcinoma

From the Division of Gastroenterology, University of Michigan, Ann Arbor, MI. Address reprint requests to: Anna Lok, M.D., Division of Gastroenterology, University of Michigan Medical Center, 3912 Taubman Center, Ann Arbor, MI 48109-0362. E-mail: aslok@umich.edu; fax: 734-936-7392.

Copyright (C) 2004 by the American Association for the Study of Liver Diseases.

Published online in Wiley InterScience (www.interscience.wiley.com).

DOI 10.1002/hep.20455 cluding those outside of Japan, reported that hepatocellular carcinoma (HCC) development is less frequent and occurs at an older age in patients with genotype B. ${ }^{7,8,10}$ These data indicate that a shorter duration of high levels of $\mathrm{HBV}$ replication and less active necroinflammation may contribute to a more favorable outcome among patients with genotype B. However, Kao et al. from Taiwan found that genotype B (all subtype Ba) was more common in patients with HCC aged less than 50 years, suggesting that genotype $\mathrm{B}$ may be associated with accelerated progression to HCC. ${ }^{6}$ This finding is paradoxical and needs to be confirmed.

There is a paucity of data on the clinical course of patients with genotypes other than B and C. One study from Spain reported that $\mathrm{HBeAg}$ seroconversion rates were similar in patients with genotypes $\mathrm{A}$ and $\mathrm{D}$, but sustained biochemical and virological remission was more common in patients with genotype A who had HBeAg seroconversion. ${ }^{11}$ Patients with genotype A also had a higher rate of HBsAg clearance. However, the need for liver transplantation and the deaths related to liver disease were comparable between patients with genotypes $A$ and $D$. In this study, patients with genotype $F$ were more likely to die from liver disease than those with genotypes A or $\mathrm{D}$, but only 19 patients with genotype $\mathrm{F}$ were included.

To date there has been no published study comparing the rate of $\mathrm{HBeAg}$ seroconversion, activity of liver disease, and rate of progression to cirrhosis and HCC among patients with all known HBV genotypes. The lack of such studies is related to the preponderance of 1 or $2 \mathrm{HBV}$ genotypes in most geographical regions. The finding of HBV genotypes A to G in the United States permits studies that compare the clinical course of HBV infection among patients with a wider spectrum of HBV genotypes. In one cross-sectional study of 694 patients in the United States, genotypes $\mathrm{B}$ and $\mathrm{D}$ were associated with a lower prevalence of $\mathrm{HBeAg}$ than genotype $\mathrm{A}$, while genotype $\mathrm{B}$ was associated with a lower rate of hepatic decompensation compared to genotype A, C, or D. ${ }^{3}$ However, other factors such as differences in ethnic/racial background, age at onset and duration of infection, and exposures to alcohol/environmental toxins rather than HBV genotypes may have contributed to the differences in clinical manifestations.

\section{HBV Genotypes and Treatment Response}

HBV genotype has been reported to correlate with response to interferon treatment in several studies. Two 

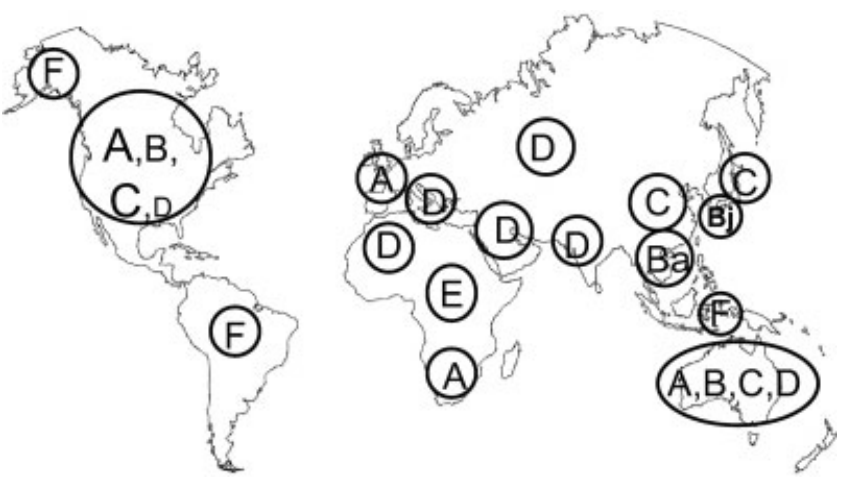

Fig. 1: Geographic distribution of hepatitis B virus genotypes.

studies from Asia found that patients with HBV genotype $\mathrm{B}$ had a higher rate of $\mathrm{HBeAg}$ seroconversion compared to those with genotype C. ${ }^{12,13}$ One study from Germany reported that patients with genotype $\mathrm{A}$ had a higher rate of $\mathrm{HBeAg}$ seroconversion than those with genotype D. ${ }^{14}$ Although all 3 studies involved small numbers of patients, these findings were confirmed by a recent study of pegylated interferon (IFN), where $\mathrm{HBeAg}$ seroconversion occurred more often in patients with genotypes A (47\%) and B (44\%) than in those with genotypes C (28\%) and D (25\%). ${ }^{15}$ Whether HBV genotypes play a role in IFN response among patients with HBeAg-negative chronic hepatitis has not been determined.

Unlike IFN, a correlation between HBV genotype and response to lamivudine or adefovir dipivoxil therapy has not been demonstrated. Several studies in Asia, all involving small numbers of patients and varying duration of lamivudine treatment, showed that HBeAg seroconversion and breakthrough infection occurred in similar proportions of patients with genotypes B and C. ${ }^{16,17}$ However, two studies, one in $\mathrm{HBeAg}$-positive and one in $\mathrm{HBeAg}$-negative patients found that patients with genotype $\mathrm{B}$ were more likely to sustain their response when treatment was discontinued. ${ }^{18,19}$ A study of 78 German patients reported that lamivudine-resistant mutants emerged more rapidly in those with genotype A versus D, but a correlation with response was not reported. ${ }^{20}$ Retrospective analysis of phase III clinical trials of adefovir dipivoxil found that all HBV genotypes resulted in a similar decrease in serum HBV DNA levels, but a correlation with $\mathrm{HBeAg}$ seroconversion could not be determined because of the small number of patients with $\mathrm{HBeAg}$ seroconversion. ${ }^{21}$

\section{HBV Genotypes and Outcome of Acute HBV Infection}

There is very little information on the correlation between HBV genotypes and the outcome of acute HBV infection. One study of 65 patients in Switzerland found that $80 \%$ of patients with acute hepatitis B had genotype $\mathrm{D}$, while $80 \%$ patients with chronic hepatitis B had genotype A. ${ }^{22}$ Another study found that $12 \%$ of 531 Japanese patients with chronic $\mathrm{HBV}$ infection had genotype $\mathrm{B}$ in contrast to $39 \%$ of 61 patients with acute hepatitis B. ${ }^{23}$ These data suggest that different HBV genotypes may be associated with different rates of progression from acute to chronic $\mathrm{HBV}$ infection. Alternatively, the data may indicate a temporal change in predominant HBV genotype due to immigration or a shift in mode of transmission.

In this issue of HePATOLOGY, Garfein et al. reported an outbreak of acute hepatitis B. ${ }^{24}$ Of the 21 patients identified, 20 were American Indians, and 20 admitted to injecting illicit drugs. Eleven patients were hospitalized, and 10 had fulminant hepatitis; all 10 with fulminant hepatitis died. The high mortality rate led to further testing to identify the viral strain and other risk factors that contributed to the severity of the disease.

Full-length HBV genomic sequences were available on 7 patients with fulminant hepatitis and 1 control with nonfulminant hepatitis. A partial sequence was available on 1 additional control. All sequences were classified as genotype D; analysis of hepatitis B cases in the U.S. Acute Liver Failure Study also found a high prevalence of genotype D. ${ }^{25}$ Three sequences from the fulminant cases were identical and represented the major sequence of the outbreak strain; sequences from the remaining 4 fulminant cases differed by 1 to 9 nucleotides, while sequences from the 2 controls differed by 2 to 9 nucleotides. These data confirmed a common source outbreak and also demonstrated that the HBV strain identified did not invariably lead to a fulminant course. Sequences from additional controls will help to strengthen this point.

The authors found many nucleotide and amino acid changes between the major sequence in this outbreak and other genotype $\mathrm{D}$ reference sequences. These differences by no means prove that the HBV strain in this study is more virulent. Indeed, precore stop codon and core promoter mutations had previously been thought to be responsible for the fulminant course in several outbreaks and case series, ${ }^{26-29}$ but these same mutations were also found in the source patients who were frequently asymptomatic carriers and in many patients with chronic HBV infection. Furthermore, full-length HBV genomic sequencing in other case series of fulminant hepatitis B failed to identify mutations that are consistently present. ${ }^{30}$ The finding of more frequent and heavier exposure to alcohol, acetaminophen, and injected methamphetamine or cocaine prior to hospitalization and hepatitis $\mathrm{C}$ coinfection in all case patients suggests that cofactors that cause liver injury may be more important than viral factors in the fulminant course in the current 
study. Similar observation was reported by the U.S. Acute Liver Failure Study Group. Among the patients with hepatitis $\mathrm{A}$ or $\mathrm{B}$, those who had measurable acetaminophen levels had more pronounced aminotransferase elevations, suggesting that acetaminophen enhances hepatocellular injury in the setting of acute viral hepatitis. ${ }^{31}$

In summary, there is increasing evidence that HBV genotype correlates with clinical outcomes of chronic $\mathrm{HBV}$ infection and response to treatment. The evidence for a clinical difference is stronger between genotypes $\mathrm{B}$ and $\mathrm{C}$, and in response to IFN but not nucleoside or nucleotide treatment. The exact reason(s) why HBV genotype may be related to clinical outcomes is not clear. It is possible that different genotypes may be associated with differences in replication fitness and expression of immune epitopes. There is also a clear association between HBV genotypes and precore and core promoter mutations. While the story of HBV genotypes continues to unfold at a rapid pace, genotyping should remain a research tool until the time when knowledge of the HBV genotype can be used to predict the risk of adverse outcomes (fulminant hepatitis, cirrhosis, or HCC) or to guide treatment decisions (choice or duration of therapy).

\section{SCOTT K. FUnG \\ ANNA S. F. LOK Division of Gastroenterology University of Michigan Ann Arbor, MI}

\section{References}

1. Chu CJ, Lok AS. Clinical significance of hepatitis B virus genotypes. HEPATOLOGY 2002;35:1274-1276.

2. Arauz-Ruiz P, Norder H, Robertson BH, Magnius LO. Genotype H: a new Amerindian genotype of hepatitis B virus revealed in Central America. J Gen Virol 2002;83:2059-2073.

3. Chu CJ, Keeffe EB, Han SH, Perrillo RP, Min AD, Soldevila-Pico C, Carey W, et al. Hepatitis B virus genotypes in the United States: results of a nationwide study. Gastroenterology 2003;125:444-451.

4. Shiina S, Fujino H, Uta Y, Tagawa K, Unuma T, Yoneyama M, Ohmori $\mathrm{T}$, et al. Relationship of HBsAg subtypes with $\mathrm{HBeAg} /$ anti-HBe status and chronic liver disease. Part I: Analysis of 1744 HBsAg carriers. Am J Gastroenterol 1991;86:866-871.

5. Lindh M, Hannoun C, Dhillon AP, Norkrans G, Horal P. Core promoter mutations and genotypes in relation to viral replication and liver damage in East Asian hepatitis B virus carriers. J Infect Dis 1999;179:775-782.

6. Kao JH, Chen PJ, Lai MY, Chen DS. Hepatitis B genotypes correlate with clinical outcomes in patients with chronic hepatitis B. Gastroenterology 2000;118:554-559.

7. Sumi H, Yokosuka O, Seki N, Arai M, Imazeki F, Kurihara T, et al. Influence of hepatitis $\mathrm{B}$ virus genotypes on the progression of chronic type B liver disease. Hepatology 2003;37:19-26.

8. Orito E, Mizokami M, Sakugawa H, Michitaka K, Ishikawa K, Ichida T, et al. A case-control study for clinical and molecular biological differences between hepatitis B viruses of genotypes B and C. Japan HBV Genotype Research Group. Hepatology 2001;33:218-223.

9. Chu CJ, Hussain M, Lok AS. Hepatitis B virus genotype B is associated with earlier HBeAg seroconversion compared with hepatitis B virus genotype C. Gastroenterology 2002;122:1756-1762.
10. Ding X, Mizokami M, Yao G, Xu B, Orito E, Ueda R, et al. Hepatitis B virus genotype distribution among chronic hepatitis $\mathrm{B}$ virus carriers in Shanghai, China. Intervirology 2001;44:43-47.

11. Sanchez-Tapias JM, Costa J, Mas A, Bruguera M, Rodes J. Influence of hepatitis $B$ virus genotype on the long-term outcome of chronic hepatitis B in western patients. Gastroenterology 2002;123:1848-1856.

12. Kao JH, Wu NH, Chen PJ, Lai MY, Chen DS. Hepatitis B genotypes and the response to interferon therapy. J Hepatol 2000;33:998-1002.

13. Wai CT, Chu CJ, Hussain M, Lok AS. HBV genotype B is associated with better response to interferon therapy in $\mathrm{HBeAg}(+)$ chronic hepatitis than genotype C. Hepatology 2002;36:1425-1430.

14. Erhardt A, Reineke U, Blondin D, Gerlich WH, Adams O, Heintges T, et al. Mutations of the core promoter and response to interferon treatment in chronic replicative hepatitis B. HEPATOLOGY 2000;31:716-725.

15. Janssen HLA, Senturk H, Zeuzem S, Akarca U, Cakaloglu Y, Simon K, et al. Peginterferon alfa-2B and lamivudine combination therapy compared with peginterferon alfa-2B for chronic $\mathrm{HBeAg}$-positive hepatitis $\mathrm{B}$ : a randomized controlled trial in 307 patients [abstract]. Hepatology 2003;38:1323.

16. Kao JH, Liu CJ, Chen DS. Hepatitis B viral genotypes and lamivudine resistance. J Hepatol 2002;36:303-304.

17. Yuen MF, Wong DK, Sablon E, Yuan HJ, Sum SM, Hui CK, et al. Hepatitis B virus genotypes B and C do not affect the antiviral response to lamivudine. Antivir Ther 2003;8:531-534.

18. Chien RN, Yeh CT, Tsai SL, Chu CM, Liaw YF. Determinants for sustained HBeAg response to lamivudine therapy. HePatology 2003;38: 1267-1273.

19. Fung SK, Wong F, Hussain M, Lok ASF. Sustained response after a 2-year course of lamivudine treatment of hepatitis $\mathrm{B}$ e antigen-negative chronic hepatitis B. J Viral Hepat 2004. In press.

20. Zollner B, Petersen J, Puchhammer-Stockl E, Kletzmayr J, Sterneck M, Fischer $\mathrm{L}$, et al. Viral features of lamivudine resistant hepatitis $\mathrm{B}$ genotypes A and D. Hepatology 2004;39:42-50.

21. Westland C, Delaney WT, Yang H, Chen SS, Marcellin P, Hadziyannis S, et al. Hepatitis B virus genotypes and virologic response in 694 patients in phase III studies of adefovir dipivoxil. Gastroenterology 2003;125:107-116.

22. Mayerat C, Mantegani A, Frei PC. Does hepatitis B virus (HBV) genotype influence the clinical outcome of HBV infection? J Viral Hepat 1999;6: 299-304.

23. Imamura T, Yokosuka O, Kurihara T, Kanda T, Fukai K, Imazeki F, et al. Distribution of hepatitis $\mathrm{B}$ viral genotypes and mutations in the core promoter and precore regions in acute forms of liver disease in patients from Chiba, Japan. Gut 2003;52:1630-1637.

24. Garfein RS, Bower WA, Loney CM, Hutin YJF, Xia GL, Jawanda J, et al. Factors associated with fulminant liver failure during an outbreak among injection drug users with acute hepatitis B. HePATOLOGY 2004;40:865-873.

25. Wai CT, Fontana RJ, Polson J, Hussain M, Shakil AO, Han SHB, et al. Clinical outcome and virological characteristics of hepatitis B related acute liver failure in the United States. J Viral Hepat 2004. In press.

26. Sato S, Suzuki K, Akahane Y, Akamatsu K, Akiyama K, Yunomura K, et al. Hepatitis $B$ virus strains with mutations in the core promoter in patients with fulminant hepatitis. Ann Intern Med 1995;122:241-248.

27. Kosaka Y, Takase K, Kojima M, Shimizu M, Inoue K, Yoshiba M, et al. Fulminant hepatitis B: induction by hepatitis B virus mutants defective in the precore region and incapable of encoding e antigen. Gastroenterology 1991;100:1087-1094.

28. Omata M, Ehata T, Yokosuka O, Hosoda K, Ohto M. Mutations in the precore region of hepatitis $\mathrm{B}$ virus DNA in patients with fulminant and severe hepatitis. N Engl J Med 1991;324:1699-1704.

29. Liang TJ, Hasegawa K, Rimon N, Wands JR, Ben-Porath E. A hepatitis B virus mutant associated with an epidemic of fulminant hepatitis. N Engl J Med 1991;324:1705-1709.

30. Sterneck M, Gunther S, Santantonio T, Fischer L, Broelsch CE, Greten H, et al. Hepatitis B virus genomes of patients with fulminant hepatitis do not share a specific mutation. HePATOLOGY 1996;24:300-306.

31. Polson JE, Ocama P, Larson AM, Hynan L, Lalani EK, Harrison ME, Lee WM. Role of acetaminophen in acute liver failure due to viral hepatitis [abstract]. Hepatology 2003;38:544A. 